\title{
Fast Neuroprotection (Fast-NPRX) for Acute Ischemic Stroke Victims: the Time for Treatment Is Now
}

\author{
Paul A. Lapchak
}

Received: 18 October 2013 / Accepted: 23 October 2013 / Published online: 7 November 2013

(C) Springer Science+Business Media New York 2013

\section{Introduction}

Since the inception of Translational Stroke Research, numerous significant scientific breakthroughs have been published as peer-reviewed contributions, and some have lead the way for significant advances in the stroke field, opening up new ways to think about stroke therapy research and development [1-5], animal models [6-9], mechanisms of injury and the ischemic cascade [3, 10-14], and clinical trials [1, 15-18]. Many of the scientific advances are being directly applied to discover therapeutic approaches, but there remain some gaps in the systematic approaches being used to treat stroke patients. The best use or way of using neuroprotective agents and the clinical trial to adequately test them is somewhat of an unfinished puzzle. We have yet to put the pieces together to assemble a coherent picture and have success with a neuroprotectant.

"Learning is not attained by chance, it must be sought for with ardor and attended to with diligence."-Abigail Adams (1744-1818).

\section{Translational Stroke Research: Ways and Means}

The development of crucial therapies for acute ischemic stroke (AIS) has come to a standstill in many settings including the academia and industry, not because of lack of

\section{P. A. Lapchak ( $\triangle)$}

Department of Neurology and Neurosurgery, Cedars-Sinai Medical

Center, Advanced Health Sciences Pavilion, Rm 8305, 127 S. San

Vicente Blvd, Los Angeles, CA 90048, USA

e-mail: paul.lapchak@cshs.org innovation, novel drugs, or efficacy in standardized accepted animal models, but for two other primary causes. First, for academics, research has slowed or even stopped in some laboratories due to the lack of government and private funding support for translational stroke research. Second, in the pharmaceutical and biotechnology industry, development of novel drugs is not being pursued due to the failure of many highimpact clinical trials (e.g., SAINT, DIAS, NEST) and their cosmic repercussions. For example, the development of novel drug approaches [19-22], thrombolytics [23-26], and devices [27-29] has slowed or halted due to late-stage clinical trial futility even with some efficacy in early rounds of clinical trials. With the exception of tissue plasminogen activator (rtPA) [30] and tenecteplase [31, 32, but also see 33], which has a higher fibrin binding specificity than rt-PA and possibly greater resistance to inactivation by plasminogen activator inhibitor-1 (PAI-1, serpin-1), an endogenous inhibitor of plasminogen activator compared to rt-PA, there continues to be a lack of significant efficacy of all forms of treatment in a diverse and heterogeneous patient population. It should be noted that both thrombolytics were equally efficacious in preclinical studies [34].

There is the perception amongst some in the community that current animal models may be inadequate for stroke therapy development. This article hypothesizes that the animal models used for the development of neuroprotective agents are more than adequate $[35,36]$, and one model has even been described as the gold standard [7-9] for drug development. It appears that the failure of many clinical trials described in the seminal review by O'Collins et al. [37] and in many recent reviews [7, 38, 39] may not only be related to poor drug selection criteria [40, 41], but also to clinical trial design, in particular, time to treatment exceeding that which could be extrapolated from translational research studies. Since a revolutionary way to treat stroke is immediately necessary, the 
utilization of established advanced clinical networks such as field administration of stroke therapy - magnesium (FASTMAG), and novel screening methods such as that used by the Regensburg stroke mobile project (RSMP) transcranial sonography units is required to help diagnose stroke in the field in order to provide the patient with the best possible opportunity for neuroprotective treatment and subsequent recovery.

\section{The FAST-MAG Network}

The establishment of the impressive FAST-MAG network by Saver and colleagues [42-44] beginning in 2003, supported by the National Institutes of Health (NIH), is a major accomplishment in the field of stroke victim care. The purpose of FAST-MAG, a multicenter, randomized, double-blind trial, is to demonstrate that paramedic initiation of the neuroprotective agent magnesium sulfate in the field is an effective and safe treatment for acute stroke. The network has allowed the Los Angeles clinical community to address some of the basic therapeutic window treatment concerns related to neuroprotection in stroke. Because of the rapid pace of developments in FAST-MAG, theoretically, it is now possible to effectively treat patients in the field (i.e., emergency medical services (EMS) vehicles) within the "golden hour," the time frame where brain tissue can still be salvaged (see below) [45] to minimize stroke damage. This could not have been accomplished without the validated Los Angeles Prehospital Stroke Screen (LAPSS) [22], mobile informed consent documentation $[46,47]$ and other evolving methods to diagnose stroke in the field (see below).

\section{The RSMP Network}

The Regensburg project is an advanced network of mobile paramedics and stroke neurologists with the background necessary to perform and accurately read transcranial color-coded sonography (TCCS) in the field [48]. The major advantage of this network is the ability of paramedics and clinicians to perform the studies en route to the hospital. In the preliminary study conducted in 2008, there was an $80 \%$ efficiency rate of vessel visualization, which could be accomplished within 2 min [49]. In the follow-up trial conducted in 2010-2011, 113 patients were enrolled, and the effectiveness of field diagnosis was at the $90 \%$ level for positive prediction of a middle cerebral artery (MCA) occlusion and $98 \%$ for negative prediction. The authors indicated that TCCS examination was completed within $5.6 \mathrm{~min}$ of reaching the stroke victim in the field, and subsequent transport to the hospital for care was accomplished within $53 \mathrm{~min}$. More recently, Holscher et al. [50] have delved further into the mobile brain rescue units that are available not only in Germany, but the state of the art will soon be available in San Diego, CA. In Germany, prehospital ultrasound can be done in both ambulances and helicopters almost guaranteeing rapid treatment to stroke victims. One hour is a modest time frame to begin to treat patients with either a thrombolytic or a neuroprotective agent to prevent or reverse ischemia-induced neurodegeneration [51].

\section{Thrombolytic Therapy}

The thrombolytic rt-PA that was first approved by the FDA in 1996 is now widely accepted as a standard of care, but it is underutilized in most communities. Alteplase has been shown to be effective up to $4.5 \mathrm{~h}$ after a stroke $[52,53]$, but it is currently FDA-approved for use within a 3-h therapeutic window. It is estimated that less than $7 \%$ of stroke patients are being treated with rt-PA in the USA [54-56] despite the fact that rt-PA is quite useful in up to $50 \%$ of patients provided with rt-PA as a treatment option, depending on the type of ischemic stroke [30]. Cost analysis based upon the utilization of rt-PA [57], within 3-4.5 h after stroke onset, clearly shows incremental benefit in patients with National Institutes of Health Stroke Scale (NIHSS) scores of 0-19, compared to no treatment. This translated into substantial benefit in terms of quality-adjusted life-years (QALY) for the stroke victim. The correlative analysis showed reduced benefit in patients with an NIHSS score $>19$ and also pointed to no significant benefit in diabetic patients or patients with atrial fibrillation [57]. We still have to deal with many important shortcomings of the drug including the fact that rt-PA does not confer neuroprotection, and there is a significant risk of hemorrhagic transformation (HT) or intracerebral hemorrhage (ICH) in approximately 3 to $6 \%$ of patients treated within $3-4.5 \mathrm{~h}$ of a stroke [58]. Moreover, the odds ratio for mortality rate increases substantially after $4 \mathrm{~h}$ [58].

Of importance to the topic of this editorial is the measure known as door-to-needle (DTN) time. The recommended DTN time for thrombolytic therapy administration is less than 60 min [59-62]. However, historically, rt-PA has been administered well in excess of that recommendation (Cochrane review [63]). For example, in the original NINDS rt-PA clinical trial [30], the administration time was stratified between 0 and $90 \mathrm{~min}$ and 91-180 min. Subsequent clinical trials have attempted to expand the therapeutic window for rt-PA [52, 64], rather than reduce the time to treatment. Eighteen years after the FDA approval of rt-PA, the treatment is still underutilized $[54,56]$, but there has been considerable improvement in DTN $[65,66]$. Recently, Saver et al. [67] completed extensive data analysis on data collected from 58,353 patients receiving rt-PA within $4.5 \mathrm{~h}$ of symptom onset. In keeping with "time is brain" (see below), the analysis of onset to treatment time (OTT) showed a direct correlation with 
measures important to the patient, including reduced mortality, reduced hemorrhage, increases functional independence, and increase time of discharge. Thus, the establishment of rapid treatment networks should now be used to our advantage, and the patient's advantage, to provide stroke victims with neuroprotective drugs which have been developed using RIGOR guidelines $[1,68,69]$, according to STAIR criteria $[70,71]$, and deemed safe using standard preclinical assessment [72-75].

\section{Time is Brain: The Need to Treat Stroke Victims Fast}

We all agree that there is a critical need for new neuroprotective or cytoprotective strategies to treat AIS to reduce morbidity, improve the quality of life (QOL) for stroke victims, and also reduce mortality. Until recently, stroke has been described as the fourth leading cause of mortality and leading cause of adult morbidity in the USA [76, 77]. It is estimated that annually, approximately 0.8 million people suffer a stroke in the USA [76, 77] and 15 million people worldwide [78]. However, since as updated definition of stroke from the American Heart Association (AHA)/American Stroke Association (ASA) [79] now includes "central nervous system infarction of brain, spinal cord or retinal cell death attributable to ischemia" and ischemic stroke with infarction with symptoms, the prevalence of stroke in society may increase. The authors also indicate that silent infarcts, which are not overtly symptomatic, are included as statistics of cerebrovascular disease. If silent infarcts are included, then $15-20 \%$ of the population would have cerebrovascular disease that must be addressed, in particular because silent infarcts are directly correlated with cognitive impairment, dementia, and Alzheimer's disease [79]. With a 2013 worldwide population of 7,186,451,126 [80], the estimated population with cerebrovascular disease escalates to 1.4 billon.

Time is brain is not only a well-known phrase, but it is based upon calculations reviewed by Saver [81], and reiterated by Holscher et al. [50]. Basically, every minute following an ischemic event, such as large or small vessel occlusion, $2 \times$ $10^{6}$ neurons die per minute and $14 \times 10^{9}$ synapses are lost, with an estimated $130 \times 10^{9}$ neurons in the human brain, $22 \times 10^{6}$ in the forebrain, representing $0.00153-0.0169 \%$ of neurons in the human brain. Within the current DTN for rt-PA, it can be estimated that a stroke patient loses $120 \times 10^{6}$ neurons if treated within $60 \mathrm{~min}$. To put this neuronal loss into perspective, the recent SAINT trial used a mean time to treatment of $3.76 \mathrm{~h}[19,20]$ (7.52 million neurons) and the NEST trial (16 $\mathrm{h}$ or 32 million neurons) [27-29, 82]. Clearly, we should strive to provide patients with a neuroprotective therapy that can be administered a soon as possible after confirmation of a stroke, and if possible, it should not be dependent upon the type of stroke with which the patient presents. Why wait to treat?

\section{Neuroprotective Drug Research and Development}

Despite the lack of efficacy of select neuroprotective molecules that have been tested in modern stroke clinical trials [37], significant research advances have been made using preclinical and translational models [1, 4, 8, 9, 39, 83-85]. Using a variety of transient or permanent rodent, rabbit, and primate ischemia models that in some way recapitulate one or more of the processes involved in ischemia-induced neurodegeneration and clinical deficits, my fellow stroke researchers have become expert at developing neuroprotective molecules that can be utilized to treat stroke $[1,4,8,9,39$, 83-85]. Why have these advances been misused or not used at all? The answer lies within the basic design of recent clinical trials.

For years, we have been attempting to increase the therapeutic window for drugs because the infrastructure to treat patients quickly was not established. This is not only true for unproven experimental neuroprotectants, which predominantly are single-target drugs [37], but also for thrombolytics [52] and devices $[29,82]$. This has universally led to the failure of all approaches except FDA-approved rt-PA [30]. With the development and implementation of the FAST-MAG approach and RSMP, we now have the opportunity to rapidly treat patients within the golden hour before there is extensive neuronal loss. Moreover, since recent research has proposed that pleiotropic agents may be required to treat stroke $[3,86$, $87]$ in order to provide protection to the neurovascular unit $[12,51,88]$, block multiple pathways of the ischemic cascade and possibly even activate trophic support mechanisms or provide neurotrophic support for recovery and regeneration, we have some insight into drug classes that may be most effective. Theoretically, all neuroprotectant drug candidates could be used immediately following patient presentation to offer the best chance of success. Since it is rational to provide neuroprotection as soon as possible, during the hyperacute phase [89], initial trials should attempt to do so.

\section{Conclusions}

The Future of Translational Stroke Research is Now!

The pieces of the puzzle described in the article are slowly coming together, but must be fully assembled both nationally and internationally, so that we have a reasonable approach to treating stroke victims worldwide. Even though this may not guarantee success, it will increase the probability that patients will be provided an option that could increase QOL. Using established networks with functional and validated diagnostic screens, prepared and trained EMS staff, and mobile informed consent, the goal of efficacious neuroprotection in stroke patients can be achieved. Since the goal is protection of the 
neurovascular unit as a whole, an efficacious lipophilic compound with blood-brain barrier (BBB) penetrating capability would be advantageous to target all cell types at risk of degeneration following an ischemic event. It is clear that neuronal loss is greater as time to treatment is delayed, so acute treatment with short DTN is highly recommended. This could eventually match the DTN guidelines for rt-PA of $60 \mathrm{~min}$ or less.

Acknowledgments This article was supported by a U01 Translational research grant NS060685 to PAL. I would also thank Dr. Tymianski for a stimulating discussion during his visit to Cedars-Sinai Medical Center.

Conflict of Interest There are no conflicts of interest to disclose.

\section{References}

1. Lapchak PA, Zhang JH, Noble-Haeusslein LJ. RIGOR guidelines: escalating STAIR and STEPS for effective translational research. Transl Stroke Res. 2013;4(3):279-85.

2. Lapchak PA, Zhang JH. Resolving the negative data publication dilemma in translational stroke research. Transl Stroke Res. 2011;2(1):1-6.

3. Lapchak PA. Emerging therapies: pleiotropic multi-target drugs to treat stroke victims. Transl Stroke Res. 2011;2(2):129-35.

4. Fagan SC, Lapchak PA, Liebeskind DS, Ishrat T, Ergul A. Recommendations for preclinical research in hemorrhagic transformation. Transl Stroke Res. 2013;4(3):322-7.

5. Bahjat FR, Gesuete R, Stenzel-Poore MP. Steps to translate preconditioning from basic research to the clinic. Transl Stroke Res. 2013;4(1):89-103.

6. Winters A, Taylor JC, Ren M, Ma R, Liu R, Yang SH. Transient focal cerebral ischemia induces long-term cerebral vasculature dysfunction in a rodent experimental stroke model. Transl Stroke Res. 2012;3(2): 279-85.

7. Turner RJ, Jickling GC, Sharp FR. Are underlying assumptions of current animal models of human stroke correct: from STAIRs to high hurdles? Transl Stroke Res. 2011;2(2):138-43.

8. Tajiri N, Dailey T, Metcalf C, Mosley YI, Lau T, Staples M, et al. In vivo animal stroke models: a rationale for rodent and non-human primate models. Transl Stroke Res. 2013;4(3):308-21.

9. Lapchak PA. Translational stroke research using a rabbit embolic stroke model: a correlative analysis hypothesis for novel therapy development. Transl Stroke Res. 2010;1(2):96-107.

10. Ahmad M, Graham SH. Inflammation after stroke: mechanisms and therapeutic approaches. Transl Stroke Res. 2010;1(2):74-84.

11. Vemuganti R. The microRNAs and stroke: no need to be coded to be counted. Transl Stroke Res. 2010;1(3):158-60.

12. Elgebaly MM, Ogbi S, Li W, Mezzetti EM, Prakash R, Johnson MH, et al. Neurovascular injury in acute hyperglycemia and diabetes: a comparative analysis in experimental stroke. Transl Stroke Res. 2011;2(3):391-8.

13. Davis CM, Fairbanks SL, Alkayed NJ. Mechanism of the sex difference in endothelial dysfunction after stroke. Transl Stroke Res. 2013;4(4):381-9.

14. Herson PS, Palmateer J, Hurn PD. Biological sex and mechanisms of ischemic brain injury. Transl Stroke Res. 2013;4(1):413-9.

15. Fagan SC, Cronic LE, Hess DC. Minocycline development for acute ischemic stroke. Transl Stroke Res. 2011;2(2):202-8.
16. Fujii M, Yan J, Rolland WB, Soejima Y, Caner B, Zhang JH. Early brain injury, an evolving frontier in subarachnoid hemorrhage research. Transl Stroke Res. 2013;4(4):432-46.

17. Huang B, Khatibi NH, Tong L, Yan P, Xie P, Zhang JH. Magnesium sulfate treatment improves outcome in patients with subarachnoid hemorrhage: a meta-analysis study. Transl Stroke Res. 2010;1(2):108-12.

18. Switzer JA, Sikora A, Ergul A, Waller JL, Hess DC, Fagan SC. Minocycline prevents IL-6 increase after acute ischemic stroke. Transl Stroke Res. 2012;3(3):363-8.

19. Lees KR, Zivin JA, Ashwood T, Davalos A, Davis SM, Diener HC, et al. NXY-059 for acute ischemic stroke. N Engl J Med. 2006;354(6):588-600.

20. Shuaib A, Lees KR, Lyden P, Grotta J, Davalos A, Davis SM, et al. NXY-059 for the treatment of acute ischemic stroke. N Engl J Med. 2007;357(6):562-71.

21. Ehrenreich H, Weissenborn K, Prange H, Schneider D, Weimar C, Wartenberg K, et al. Recombinant human erythropoietin in the treatment of acute ischemic stroke. Stroke. 2009;40(12):e647-56.

22. Saver JL. Targeting the brain: neuroprotection and neurorestoration in ischemic stroke. Pharmacotherapy. 2010;30(7 Pt 2):62S-9.

23. Dafer RM, Biller J. Desmoteplase in the treatment of acute ischemic stroke. Expert Rev Neurother. 2007;7(4):333-7.

24. Furlan AJ, Eyding D, Albers GW, Al-Rawi Y, Lees KR, Rowley HA, et al. Dose escalation of Desmoteplase for Acute Ischemic Stroke (DEDAS): evidence of safety and efficacy 3 to 9 hours after stroke onset. Stroke. 2006;37(5):1227-31.

25. Hacke W, Albers G, Al-Rawi Y, Bogousslavsky J, Davalos A, Eliasziw M, et al. The Desmoteplase in Acute Ischemic Stroke Trial (DIAS): a phase II MRI-based 9-hour window acute stroke thrombolysis trial with intravenous desmoteplase. Stroke. 2005;36(1):66-73.

26. Hacke W, Furlan AJ, Al-Rawi Y, Davalos A, Fiebach JB, Gruber F, et al. Intravenous desmoteplase in patients with acute ischaemic stroke selected by MRI perfusion-diffusion weighted imaging or perfusion CT (DIAS-2): a prospective, randomised, double-blind, placebo-controlled study. Lancet Neurol. 2009;8(2):141-50.

27. Kasner SE, Rose DZ, Skokan A, Walker MG, Shi J, Streeter J, et al. Transcranial laser therapy and infarct volume. Stroke. 2013;44(7): 2025-7. doi:10.1161/STROKEAHA.113.000870.

28. Zivin JA, Albers GW, Bornstein N, Chippendale T, Dahlof B, Devlin $\mathrm{T}$, et al. Effectiveness and safety of transcranial laser therapy for acute ischemic stroke. Stroke. 2009;40(4):1359-64.

29. Photothera. PhotoThera NEST-3 trial halted due to futility. 2013 http://www.tsijournal.com/clinical-trial-updates-body. Accessed 17 Oct 2013

30. NINDS. Tissue plasminogen activator for acute ischemic stroke. The National Institute of Neurological Disorders and Stroke rt-PA Stroke Study Group. N Engl J Med. 1995;333(24):1581-7.

31. Parsons M, Spratt N, Bivard A, Campbell B, Chung K, Miteff F, et al. A randomized trial of tenecteplase versus alteplase for acute ischemic stroke. N Engl J Med. 2012;366(12):1099-107.

32. Parsons MW, Miteff F, Bateman GA, Spratt N, Loiselle A, Attia J, et al. Acute ischemic stroke: imaging-guided tenecteplase treatment in an extended time window. Neurology. 2009;72(10):915-21.

33. Haley Jr EC, Thompson JL, Grotta JC, Lyden PD, Hemmen TG, Brown DL, et al. Phase IIB/III trial of tenecteplase in acute ischemic stroke: results of a prematurely terminated randomized clinical trial. Stroke. 2010;41(4):707-11.

34. Lapchak PA, Araujo DM, Zivin JA. Comparison of tenecteplase with Alteplase on clinical rating scores following small clot embolic strokes in rabbits. Exp Neurol. 2004;185(1):154-9.

35. O'Collins VE, Donnan GA, Howells DW. History of animal models of stroke. Int J Stroke. 2011;6(1):77-8.

36. Casals JB, Pieri NC, Feitosa ML, Ercolin AC, Roballo KC, Barreto RS, et al. The use of animal models for stroke research: a review. Comp Med. 2011;61(4):305-13. 
37. O'Collins VE, Macleod MR, Donnan GA, Horky LL, van der Worp BH, Howells DW. 1,026 experimental treatments in acute stroke. Ann Neurol. 2006;59(3):467-77.

38. Liebeskind DS, Kasner SE. Neuroprotection for ischaemic stroke: an unattainable goal? CNS Drugs. 2001;15(3):165-74.

39. Minnerup J, Sutherland BA, Buchan AM, Kleinschnitz C. Neuroprotection for stroke: current status and future perspectives. Int J Mol Sci. 2012;13(9):11753-72.

40. Feuerstein GZ, Zaleska MM, Krams M, Wang X, Day M, Rutkowski JL, et al. Missing steps in the STAIR case: a translational medicine perspective on the development of NXY-059 for treatment of acute ischemic stroke. J Cereb Blood Flow Metab. 2008;28(1):217-9.

41. Savitz SI. Cosmic implications of NXY-059. Stroke. 2009;40(3 Suppl):S115-8.

42. Meloni BP, Cross JL, Brookes LM, Clark VW, Campbell K, Knuckey NW. FAST-Mag protocol with or without mild hypothermia (35 degrees C) does not improve outcome after permanent MCAO in rats. Magnes Res. 2013;26(2):67-73. Off Org Int Soc Dev Res Magnes.

43. Gorelick PB, Ruland S. IMAGES and FAST-MAG: magnesium for acute ischaemic stroke. Lancet Neurol. 2004;3(6):330.

44. Saver JL, Kidwell C, Eckstein M, Starkman S, Investigators F-MPT. Prehospital neuroprotective therapy for acute stroke: results of the Field Administration of Stroke Therapy-Magnesium (FAST-MAG) pilot trial. Stroke. 2004;35(5):e106-8.

45. Saver JL, Smith EE, Fonarow GC, Reeves MJ, Zhao X, Olson DM, et al. The "golden hour" and acute brain ischemia: presenting features and lytic therapy in $>30,000$ patients arriving within 60 minutes of stroke onset. Stroke. 2010;41(7):1431-9.

46. Sanossian N, Starkman S, Eckstein M, Stratton S, Pratt F, Conwit R, et al. Intercontinental elicitation of informed consent for enrollment in stroke research. Cerebrovasc Dis. 2010;30(3):323-4.

47. Sanossian N, Starkman S, Liebeskind DS, Ali LK, Restrepo L, Hamilton S, et al. Simultaneous ring voice-over-Internet phone system enables rapid physician elicitation of explicit informed consent in prehospital stroke treatment trials. Cerebrovasc Dis. 2009;28(6):539 44

48. Schlachetzki F, Herzberg M, Holscher T, Ertl M, Zimmermann M, Ittner KP, et al. Transcranial ultrasound from diagnosis to early stroke treatment: part 2: prehospital neurosonography in patients with acute stroke: the Regensburg stroke mobile project. Cerebrovasc Dis. 2012;33(3):262-71.

49. Holscher T, Schlachetzki F, Zimmermann M, Jakob W, Ittner KP, Haslberger J, et al. Transcranial ultrasound from diagnosis to early stroke treatment. 1. Feasibility of prehospital cerebrovascular assessment. Cerebrovasc Dis. 2008;26(6):659-63.

50. Holscher T, Dunford JV, Schlachetzki F, Boy S, Hemmen T, Meyer $\mathrm{BC}$, et al. Prehospital stroke diagnosis and treatment in ambulances and helicopters - a concept paper. Am J Emerg Med. 2013;31(4): 743-7.

51. Moskowitz MA, Lo EH, Iadecola C. The science of stroke: mechanisms in search of treatments. Neuron. 2010;67(2):181-98.

52. Hacke W, Kaste M, Bluhmki E, Brozman M, Davalos A, Guidetti D, et al. Thrombolysis with alteplase 3 to 4.5 hours after acute ischemic stroke. N Engl J Med. 2008;359(13):1317-29.

53. Lansberg MG, Bluhmki E, Thijs VN. Efficacy and safety of tissue plasminogen activator 3 to 4.5 hours after acute ischemic stroke: a metaanalysis. Stroke. 2009;40(7):2438-41.

54. Fang MC, Cutler DM, Rosen AB. Trends in thrombolytic use for ischemic stroke in the United States. J Hosp Med. 2010;5(7):406-9.

55. Reeves MJ, Arora S, Broderick JP, Frankel M, Heinrich JP, Hickenbottom S, et al. Acute stroke care in the US: results from 4 pilot prototypes of the Paul Coverdell National Acute Stroke Registry. Stroke. 2005;36(6):1232-40.

56. Schwamm LH, Ali SF, Reeves MJ, Smith EE, Saver JL, Messe S, et al. Temporal trends in patient characteristics and treatment with intravenous thrombolysis among acute ischemic stroke patients at get with the guidelines-stroke hospitals. Circ Cardiovasc Qual Outcome. 2013;6(5):543-9.

57. Boudreau DM, Guzauskas G, Villa KF, Fagan SC, Veenstra DL. A Model of Cost-effectiveness of Tissue Plasminogen Activator in Patient Subgroups 3 to 4.5 Hours After Onset of Acute Ischemic Stroke. Ann Emerg Med. 2012.

58. Lees KR, Bluhmki E, von Kummer R, Brott TG, Toni D, Grotta JC, et al. Time to treatment with intravenous alteplase and outcome in stroke: an updated pooled analysis of ECASS, ATLANTIS, NINDS, and EPITHET trials. Lancet. 2010;375(9727):1695-703.

59. Desai JA, Smith EE. Prenotification and other factors involved in rapid tPA administration. Curr Atheroscler Rep. 2013;15(7):337.

60. Olson DM, Constable M, Britz GW, Lin CB, Zimmer LO, Schwamm $\mathrm{LH}$, et al. A qualitative assessment of practices associated with shorter door-to-needle time for thrombolytic therapy in acute ischemic stroke. J Neurosci Nurs. 2011;43(6):329-36.

61. Fonarow GC, Smith EE, Saver JL, Reeves MJ, Hernandez AF, Peterson ED, et al. Improving door-to-needle times in acute ischemic stroke: the design and rationale for the American Heart Association/ American Stroke Association's Target: stroke initiative. Stroke. 2011;42(10):2983-9.

62. Fonarow GC, Smith EE, Saver JL, Reeves MJ, Bhatt DL, GrauSepulveda MV, et al. Timeliness of tissue-type plasminogen activator therapy in acute ischemic stroke: patient characteristics, hospital factors, and outcomes associated with door-to-needle times within 60 minutes. Circulation. 2011;123(7):750-8.

63. Wardlaw JM, Koumellis P, Liu M. Thrombolysis (different doses, routes of administration and agents) for acute ischaemic stroke. Cochrane Database Syst Rev. 2013;5, CD000514.

64. Bluhmki E, Chamorro A, Davalos A, Machnig T, Sauce C, Wahlgren $\mathrm{N}$, et al. Stroke treatment with alteplase given 3.0-4.5 h after onset of acute ischaemic stroke (ECASS III): additional outcomes and subgroup analysis of a randomised controlled trial. Lancet Neurol. 2009;8(12):1095-102.

65. Ricci S, Cenciarelli S, Mazzoli T. Italian guidelines on thrombolysis indications in ischaemic stroke have been revised after IST 3 trial and Cochrane review: PROS. Intern Emerg Med. 2013. doi:10.1007/ s11739-013-0987-x.

66. Costantino G, Podda GM, Bonzi M, Sbrojavacca R, Gruppo di Autoformazione Metodologica. Italian guidelines on thrombolysis indications in ischemic stroke have been revised after IST-3 trial and Cochrane revision: cons. Intern Emerg Med. 2013. doi:10. 1007/s11739-013-0986-y.

67. Saver JL, Fonarow GC, Smith EE, Reeves MJ, Grau-Sepulveda MV, Pan W, et al. Time to treatment with intravenous tissue plasminogen activator and outcome from acute ischemic stroke. JAMA. 2013;309(23):2480-8.

68. Lapchak PA. Recommendations and practices to optimize stroke therapy: developing effective translational research programs. Stroke. 2013;44(3):841-3.

69. Landis SC, Amara SG, Asadullah K, Austin CP, Blumenstein R, Bradley EW, et al. A call for transparent reporting to optimize the predictive value of preclinical research. Nature. 2012;490(7419): 187-91.

70. STAIR. Recommendations for standards regarding preclinical neuroprotective and restorative drug development. Stroke. 1999;30(12): 2752-8.

71. Saver JL, Albers GW, Dunn B, Johnston KC, Fisher M. Stroke Therapy Academic Industry Roundtable (STAIR) recommendations for extended window acute stroke therapy trials. Stroke. 2009;40(7):2594-600.

72. McKim Jr JM. Building a tiered approach to in vitro predictive toxicity screening: a focus on assays with in vivo relevance. Comb Chem High Throughput Screen. 2010;13(2):188-206.

73. Lapchak PA, KcKim JM. CeeTox ${ }^{\mathrm{TM}}$ analysis of CNB-001 a novel curcumin-based neurotrophic/neuroprotective lead compound to treat 
stroke: comparison with NXY-059 and Radicut. Transl Stroke Res. 2011;2(1):51-9.

74. Thaul S. How FDA approves drugs and regulates their safety and effectiveness. 2012. http://www.fas.org/sgp/crs/misc/R41983.pdf, Accessed 17 Oct 2013

75. FDA. The FDA's drug review process: ensuring drugs are safe and effective. 2012. http://www.fda.gov/drugs/resourcesforyou/ consumers/ucm143534.htm, Accessed 17 Oct 2013

76. Roger VL, Go AS, Lloyd-Jones DM, Adams RJ, Berry JD, Brown TM, et al. Heart disease and stroke statistics-2011 update: a report from the American Heart Association. Circulation. 2011;123(4):e18209.

77. Roger VL, Go AS, Lloyd-Jones DM, Benjamin EJ, Berry JD, Borden WB, et al. Heart disease and stroke statistics-2012 update. Circulation. 2011. doi:10.1161/CIR.0b013e31823ac046.

78. Lloyd-Jones D, Adams R, Carnethon M, De Simone G, Ferguson TB, Flegal K, et al. Heart disease and stroke statistics-2009 update: a report from the American Heart Association Statistics Committee and Stroke Statistics Subcommittee. Circulation. 2009;119(3):480-6.

79. Sacco RL, Kasner SE, Broderick JP, Caplan LR, Connors JJ, Culebras A, et al. An updated definition of stroke for the 21st century: a statement for healthcare professionals from the American Heart Association/American Stroke Association. Stroke. 2013;44(7):206489.

80. Worldometer. http://www.worldometers.info/world-population/. 2013. Accessed 17 Oct 2013
81. Saver JL. Time is brain — quantified. Stroke. 2006;37(1):263-6.

82. Lampl Y, Zivin JA, Fisher M, Lew R, Welin L, Dahlof B, et al. Infrared laser therapy for ischemic stroke: a new treatment strategy: results of the NeuroThera Effectiveness and Safety Trial-1 (NEST-1). Stroke. 2007;38(6):1843-9.

83. Leonardo CC, Robbins S, Dore S. Translating basic science research to clinical application: models and strategies for intracerebral hemorrhage. Front Neurol. 2012;3:85.

84. Cook DJ, Tymianski M. Nonhuman primate models of stroke for translational neuroprotection research. Neurotherapeutics. 2012;9(2): 371-9.

85. Cook DJ, Teves L, Tymianski M. A translational paradigm for the preclinical evaluation of the stroke neuroprotectant Tat-NR2B9c in gyrencephalic nonhuman primates. Sci Transl Med. 2012;4(154): $154 \mathrm{ra3} 3$.

86. Woodruff TM, Thundyil J, Tang SC, Sobey CG, Taylor SM, Arumugam TV. Pathophysiology, treatment, and animal and cellular models of human ischemic stroke. Mol Neurodegener. 2011;6(1):11.

87. Bordet R, Ouk T, Onteniente B, Charriaut-Marlangue C, Heurteaux C. Cerebral ischaemia: tomorrow's therapeutic tracks. Med Sci (Paris). 2009;25(10):847-54.

88. Lo EH, Rosenberg GA. The neurovascular unit in health and disease: introduction. Stroke. 2009;40(3 Suppl):S2-3.

89. Ferguson KN, Kidwell CS, Starkman S, Saver JL. Hyperacute treatment initiation in neuroprotective agent stroke trials. J Stroke Cerebrovasc Dis. 2004;13(3):109-12. 